\title{
Long-Term Follow-Up of Redo Pull-Through Procedures for Hirschsprung's Disease: Efficacy of the Endorectal Pull-Through
}

\author{
By Kathleen van Leeuwen, Daniel H. Teitelbaum, Essam A. Elhalaby, and Arnold G. Coran \\ Ann Arbor, Michigan
}

\begin{abstract}
Background/Purpose: The purpose of this study was to review the authors' 25-year experience with redo pullthrough procedures for Hirschsprung's disease including surgical technique and long-term outcome.
\end{abstract}

Methods: From 1974 to now, over 325 patients with Hirschsprung's disease have been treated at C.S. Mott Children's Hospital. This includes 30 patients referred after an unsuccessful pull-through at another hospital and 2 patients with an unsuccessful pull-through from C.S. Mott. All redo pull-throughs $(n=19)$ were performed in these patients, and their clinical courses are reviewed.

Results: Twelve patients required reoperation secondary to a mechanical problem with their first pull-through. The other 7 patients had evidence of residual segments of dilated colon leading to functional failure of their initial operation including 5 patients with documented aganglionic bowel present at the second pull-through. Ten of the patients requiring reoperation initially had an endorectal pull-through (ERPT), 5 had a Duhamel procedure, 3 had a Swenson procedure, and $1 \mathrm{had}$ a
Rehbein procedure. Choice of revision was an ERPT in 8 patients in whom an adequate rectal cuff could be developed. Additional redo procedures included a Duhamel in 8 patients and a Swenson in 3 patients. Follow-up ranges from 3 months to 23 years (mean, 13.8 years). There were no deaths in the series, and 1 patient required a third pull-through. All patients who are not neurologically impaired and are over age 3 are continent except one (94\%). Stools per day range from 1 to 10 (mean, 3.2).

Conclusions: Redo pull-through operations for Hirschsprung's disease appear to be as effective as primary procedures in terms of continence and stooling frequency. Distinct from other series, we found an ERPT to be the procedure of choice if an adequate rectal cuff was present.

J Pediatr Surg 35:829-834. Copyright (c) 2000 by W.B. Saunders Company.

INDEX WORDS: Hirschsprung's disease, endorectal pullthrough, Duhamel procedure, Swenson procedure.
$\mathbf{T}$ HE EVOLUTION of the surgical treatment of Hirschsprung's disease over the past 50 years has seen a wide variety of techniques ranging from Swenson's first-described procedure in $1948^{1}$ to the perineal onestage pull-through described by Langer et al in $1999 .^{2}$ Contributions have been made by many in an attempt to optimize a difficult operation for an often-difficult problem. Modifications by Duhamel, Soave, and others have addressed a variety of disease presentations, but also have carried with them a variety of complications. ${ }^{3-7}$ Despite the complexity of the disease and its various treatments, patients with this disease tend to do well over time. A small subgroup of patients, however, does poorly with the initial pull-through and may require a second pullthrough procedure for either mechanical or functional failure of the first operation.

From 1974 until 1999 we have cared for over 325 patients with Hirschsprung's disease at our institution. Of these patients, 30 were referred from an outside hospital with an unsuccessful initial pull-through. Thirteen of these referrals were successfully managed medically or with minor surgical procedures. Seventeen of these 30 referral patients subsequently underwent a redo pullthrough. Two additional patients who required a redo pull-through had their initial operations at our own institution. In all, we have performed redo pull-through procedures in 19 patients. These children present unique challenges, and much has been learned from their management. This report presents our experience with this group of patients.

\section{MATERIALS AND METHODS}

Patients who had undergone a redo pull-through at the C.S. Mott Children's Hospital from 1974 to 1998 were reviewed retrospectively. Patients' charts were analyzed for presentation, family history of Hirschsprung's disease, length of aganglionosis, details of all surgical procedures, episodes of enterocolitis, early and late complications, and stooling habits including continence, frequency, and need for laxatives or other medications. Follow-up information was obtained from outpatient visit notes and telephone interviews. Surgical notes and pathology reports before transfer of the patients' care to our hospital were reviewed.

From the Section of Pediatric Surgery, the Department of Surgery, The University of Michigan Medical School and C.S. Mott Children's Hospital, Ann Arbor, MI.

Presented at the 1999 Annual Meeting of the Section on Surgery of the American Academy of Pediatrics, Washington, DC, October 8-10, 1999.

Address reprint requests to Arnold G. Coran, MD, Section of Pediatric Surgery, University of Michigan Hospitals, Mott F3970, Box 0245, Ann Arbor, MI 48109.

Copyright $\odot 2000$ by W.B. Saunders Company

0022-3468/00/3506-0004\$03.00/0

doi:10.1053/js.2000.6853 
We defined reoperation as a revision of a previously performed definitive procedure for aganglionic bowel. Patients with retained septum after Duhamel operation were included if they required more than a simple division of their retained septum. Patients requiring only a sphincterotomy or myectomy were excluded. Several patients required both a redo pull-through and a sphincterotomy-myectomy either preoperatively or postoperatively, and these patients were included. We defined continence as "clean" between bowel movements. We defined an episode of enterocolitis as explosive diarrhea or abdominal distension requiring hospitalization for hydration and antibiotics. ${ }^{8}$

\section{RESULTS}

\section{Patient Population}

Thirteen of our 19 patients were boys and 6 were girls. One patient had a family history positive for Hirschsprung's disease, and one patient had Trisomy 21. Age at initial presentation of Hirschsprung's disease varied greatly with 16 patients presenting in the newborn period (range, 1 day to 2 months) and with 3 patients experiencing a long delay until diagnosis (range, 15 months to 15 years). The primary pull-through procedures included 10 endorectal pull-throughs (ERPT), 5 Duhamel procedures, 3 Swenson procedures, and 1 Rehbein procedure (Table 1).

Of the 10 patients who underwent an initial ERPT, 4 had residual or acquired aganglionosis. Three of these underwent a redo ERPT, and 1 underwent a Swenson procedure. Three ERPT patients experienced an anastomotic leak resulting in stricture formation after the initial operation, and all 3 underwent a redo ERPT procedure. One of the ERPT patients had a cuff abscess and required a redo pull-through using the Duhamel procedure because of extensive scarring of the rectal cuff. Another ERPT patient had obstruction caused by a $180^{\circ}$ twist at the anastomosis and underwent a redo ERPT. The last

Table 1. Indications for Redo Pull-Through

\begin{tabular}{llll}
\hline $\begin{array}{c}\text { Primary } \\
\text { Procedure }\end{array}$ & \multicolumn{1}{c}{$\begin{array}{c}\text { Indications for } \\
\text { Reoperation }\end{array}$} & $\begin{array}{l}\text { Secondary } \\
\text { Procedure }\end{array}$ & Year \\
\hline Swenson & Dilated colon & Duhamel & 1974 \\
Duhamel & Retained septum & Duhamel & 1974 \\
Duhamel & Fecaloma & Duhamel & 1974 \\
Swenson & Stricture & Swenson & 1974 \\
ERPT & Residual aganglionosis & Swenson & 1975 \\
Duhamel & Fecaloma & Duhamel & 1975 \\
ERPT & Residual aganglionosis & ERPT & 1975 \\
Duhamel & Retained septum/stricture & Duhamel & 1975 \\
ERPT & Abscess & Duhamel & 1975 \\
Duhamel & Retained septum & Duhamel & 1977 \\
Swenson & Retracted neorectum & ERPT & 1977 \\
ERPT & 180 ${ }^{\circ}$ twist & ERPT & 1980 \\
ERPT & Residual aganglionosis & Swenson & 1988 \\
ERPT & Leak & ERPT & 1989 \\
ERPT & Leak/stricture & ERPT & 1990 \\
ERPT & Residual aganglionosis & ERPT & 1994 \\
ERPT & Stricture & ERPT & 1996 \\
ERPT & Dilated colon & ERPT & 1997 \\
Rehbein & Residual aganglionosis & Duhamel & 1998 \\
\hline
\end{tabular}

NOTE. Note the trend toward ERPT as redo procedure in the latter half of the series.
Table 2. Length of Aganglionosis

\begin{tabular}{lc}
\hline Length of Aganglionosis & No. of Patients \\
\hline Rectum & 3 \\
Rectosigmoid & 8 \\
Distal to splenic flexure & 3 \\
Mid right colon & 1 \\
Total colonic & 1 \\
Unknown & 3 \\
\hline
\end{tabular}

ERPT patient had persistent dilatation of the colon and problems with constipation refractory to an enema program. Rectal biopsy was performed, and the results showed presence of ganglion cells. The rectal biopsy was repeated 4 years later because of continued constipation and colonic dilatation, and results showed absence of ganglion cells. The patient therefore underwent a redo ERPT with resection of a portion of dilated bowel, which on pathological examination contained ganglion cells.

Of the 5 patients who first underwent a Duhamel procedure, 3 had a retained or reformed septum and required redo Duhamels. The other 2 experienced obstruction caused by fecaloma formation in the rectal pouch and underwent redo Duhamels.

Of the 3 patients who first underwent Swenson procedures, 1 had a stricture and underwent a redo Swenson. One patient experienced persistent dilatation of the colon and underwent a revision to a Duhamel. The last patient had retraction of the neorectum at the anastomosis. Because there was a sufficient rectal cuff, this pullthrough was redone as an ERPT.

The patient who first underwent a Rehbein procedure had it revised to a Duhamel after resection of the residual aganglionic bowel.

\section{Length of Aganglionosis}

We were able to obtain information regarding the length of aganglionic bowel present at the first operation in 16 of our 19 patients. Extent of disease included 3 patients with rectal involvement only, 8 patients with standard rectosigmoid disease, 3 patients with disease distal to the splenic flexure, 1 patient with involvement distal to the midascending colon, and 1 patient with total colonic aganglionosis (Table 2).

\section{Age at Various Operations}

Seventeen of our 19 patients underwent a leveling colostomy as their first surgical intervention. The average age at colostomy was 19.3 months (range, 1 day to 15 years). Among those patients with disease diagnosed in the newborn period, the average age at colostomy was 26.5 days. Average age at first pull-through operation was 2.3 years (range, 2 days to 16 years). The average time between the first operation and the redo procedure was 32 months (range, 1 day to 7.5 years). The patient whose 
operation was revised after only 1 day was from our own institution and required revision secondary to incorrect intraoperative biopsy results. The average age at reoperation was 5.4 years (range, 14 months to 23 years).

\section{Enterocolitis}

Six of our 19 patients experienced at least 1 episode of enterocolitis requiring hospitalization after their primary pull-through (range, 1 to 5 episodes; mean, 2.8). Five of these improved after reoperation with no further episodes. One patient continued to have problems with enterocolitis and was admitted 5 separate times in the early postreoperation period. This patient underwent a myectomy and required only 1 admission for enterocolitis after that procedure. At the last follow-up in 1998 the patient had had no hospitalizations in the previous 5 years. Two of the 6 patients with enterocolitis were neurologically impaired.

\section{Follow-Up}

Follow-up from the redo pull-through procedure averaged 13.8 years (range, 3 months to 23 years). Fifteen of our 19 patients are considered continent of stool between bowel movements at last follow-up, which is $79 \%$ of the total. Of the remaining 4 patients who are not considered continent, 2 are mentally impaired; 1 of these has a permanent ostomy per his parents request because of frequent loose stools after reoperation. A third patient is too young for toilet training, and the fourth is undergoing anorectal manometry studies to best determine the cause of his 4 to 6 incontinent stools per day. If the 2 neurologically impaired patients and the patient too young for training are excluded, the percentage of children continent after reoperation is $94 \%$. Stooling frequency in the continent group averages 3.2 stools per day (range, 1 to 10).

\section{DISCUSSION}

Despite several reports of excellent results with surgical procedures for Hirschsprung's disease, a small subgroup will inevitably have complications after a pullthrough procedure. ${ }^{9-14}$ In a select group of patients, these complications can be insurmountable without the performance of a redo pull-through. We are adding this series to a number of reports in the literature of redo pull-through cases (Table 3). It is useful to examine the differences in these series to help elucidate the possible technical approaches when attempting a reoperation.

Wilcox and Kiely ${ }^{15}$ in 1998 described 20 cases, and their indications for reoperation were similar to our series including anastomotic stenosis $(\mathrm{n}=8)$, signs of obstruction or constipation $(\mathrm{n}=8)$, anocutaneous fistula $(\mathrm{n}=1)$, and enterocolitis $(\mathrm{n}=1)$. They opted for a modified 3 -stage Duhamel procedure in all but 1 of their patients

\begin{tabular}{|c|c|c|c|c|}
\hline Study & Year & $\begin{array}{l}\text { No. of } \\
\text { Cases }\end{array}$ & $\begin{array}{c}\text { Initial } \\
\text { Procedure }\end{array}$ & $\begin{array}{c}\text { Redo } \\
\text { Procedure }\end{array}$ \\
\hline $\begin{array}{l}\text { Wilcox and } \\
\text { Kiely }{ }^{15}\end{array}$ & 1998 & 20 & $\begin{array}{l}10 \text { Duhamel } \\
3 \text { Soave } \\
7 \text { Swenson }\end{array}$ & $\begin{array}{r}19 \text { Duhamel } \\
1 \text { Swenson }\end{array}$ \\
\hline Sarioglu et al ${ }^{16}$ & 1998 & 5 & $\begin{array}{l}4 \text { Swenson } \\
1 \text { ERPT/Boley }\end{array}$ & $\begin{array}{l}3 \text { Duhamel } \\
2 \text { Swenson }\end{array}$ \\
\hline Weber et al ${ }^{17}$ & 1999 & 9 & $\begin{array}{l}5 \text { Soave } \\
4 \text { Duhamel }\end{array}$ & $\begin{array}{l}7 \text { Duhamel } \\
2 \text { Soave }\end{array}$ \\
\hline Langer ${ }^{18}$ & 1999 & 9 & $\begin{array}{l}6 \text { Soave } \\
2 \text { Swenson } \\
1 \text { Duhamel }\end{array}$ & $\begin{array}{l}8 \text { Duhamel } \\
1 \text { Swenson }\end{array}$ \\
\hline Current study & 1999 & 19 & $\begin{array}{l}10 \text { ERPT } \\
5 \text { Duhamel } \\
3 \text { Swenson } \\
1 \text { Rehbein }\end{array}$ & $\begin{array}{l}8 \text { ERPT } \\
8 \text { Duhamel } \\
\text { 3 Swenson }\end{array}$ \\
\hline Total & & 62 & $\begin{array}{l}20 \text { Duhamel } \\
16 \text { Swenson } \\
25 \text { Soave/ERPT } \\
1 \text { Rehbein }\end{array}$ & $\begin{array}{l}45 \text { Duhamel } \\
7 \text { Swenson } \\
10 \text { Soave/ERPT }\end{array}$ \\
\hline
\end{tabular}

and report $70 \%$ improvement in symptoms and fecal control. Mean follow-up was 6.5 years, and average stooling frequency was 2.2 stools per day.

Sarioglu, et $\mathrm{al}^{16}$ in 1998 reported their experience with 5 reoperations for similar indications. Before redo, their patients had severe strictures in 3 cases with a total closure of the anastomotic site in 1 of these. One child had a recto-urethral fistula, and 1 had an anastomotic disruption. The choice of reoperation was a Duhamel in 3 patients and a Swenson in the other 2 patients. Average follow-up was 14 years during which the patients were reported to do well, although objective data regarding continence were not available.

Weber et $\mathrm{al}^{17}$ in 1999 presented 38 patients undergoing reoperation over a 23 -year period. Their data included 21 patients who required only myectomy and 8 patients who underwent permanent colostomy. These patients were not included in this review because they do not apply to our definition of reoperation. Only 9 patients in their series underwent formal revision of a pull-through, and, of these, indications for reoperation included retained septum $(n=4)$, enterocolitis $(n=1)$, retained aganglionic segment $(n=3)$, and necrosis of pullthrough $(n=1)$. Revisions included a Duhamel in 7 patients and a Soave in 2 patients. The authors' aggressive reoperation strategy in the 38 patients they reviewed resulted in a $90 \%$ rate of patients considered to have excellent results, although continence in the revisions was not quantified.

Langer ${ }^{18}$ reported his series of 9 repeat pull-through procedures over a 4-year period for indications that included stricture $(\mathrm{n}=3)$ and acquired aganglionosis $(\mathrm{n}=6)$. His choice of reoperation was a Duhamel in all but 1 child who underwent a revision Swenson. He found that the Duhamel was the better option for late reoperation.

Our technical approach to many of our patients was 


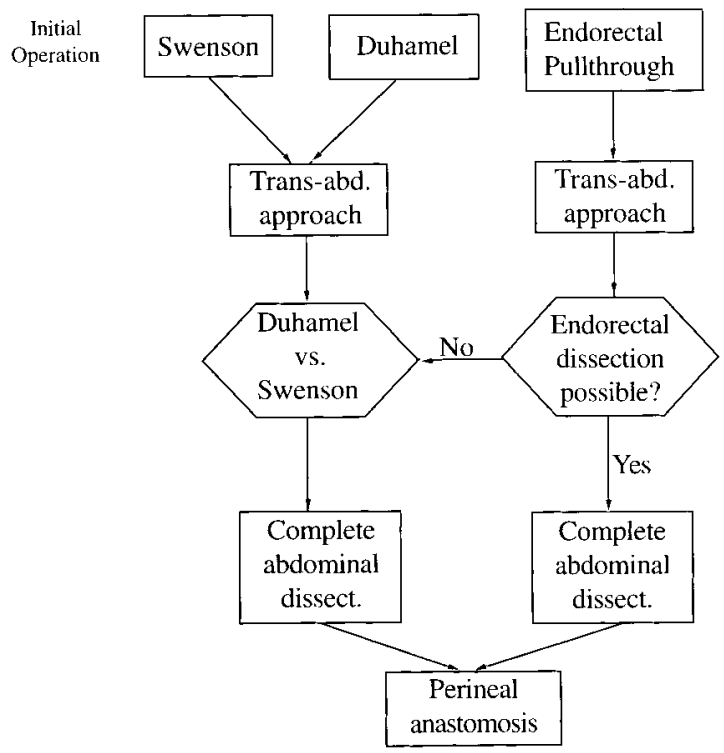

Fig 1. Algorithm for a redo pull-through after various initial pull-throughs for Hirschsprung's disease.

quite unique compared with the above series. Early in our experience we believed that a Swenson, Duhamel, and endorectal pull-through could only be redone with a Swenson or Duhamel procedure. We later discovered that the endorectal pull-through could routinely be redone with another endorectal procedure, carried out via both a transabdominal and transperineal approach. Table 1 is ordered chronologically and shows that 8 of the last 9 reoperations we performed were endorectal pull-throughs as opposed to only 1 of the first 10 reoperations. Occasionally, a Swenson procedure with a stricture and a long aganglionic segment could also be redone with an endorectal pull-through. In general, a Duhamel procedure is best redone with either another Duhamel pull-through or a Swenson procedure. The advantage of using the endorectal pull-through as a redo procedure is the elimination of the risk of damage to the nervi erigentes and the nerves to the bladder, because the dissection is done entirely within the rectal cuff. Figure 1 diagrammatically shows our approach taken to selecting a redo procedure.

Adding the data from the current study brings the total number of redo pull-throughs in these 5 series to 62 . The primary operations in these children were rather evenly distributed at 25 Soave or ERPT procedures, 20 Duhamel procedures, 16 Swenson procedures, and 1 Rehbein procedure. The reoperations performed, however, were weighted toward 1 procedure, the Duhamel. Forty-five patients underwent a Duhamel as a reoperation (71\%), 10 underwent a Soave or ERPT, and 7 underwent a Swenson procedure. Eight of the patients who underwent an ERPT as a reoperation were in our own study, and only 2 were in another series. It should be noted that the other series have excellent results as well when using the Duhamel as a reoperation.

The decision to undertake a redo pull-through is made only after all other measures of medical therapy and other less technically challenging surgical procedures have been attempted. Our patients underwent a redo pullthrough for primarily 2 reasons, aganglionosis at the proximal anastomosis and severe stricture. Pathological confirmation of ganglion cells at the point of anastomosis is not adequate assurance that aganglionosis does not exist. Interestingly, 3 of our 5 patients with residual aganglionosis had pathology reports that showed normal ganglion cells at the level of the anastomosis on their first pull-through operation. The etiology of this loss of ganglion cells is unknown. West et $\mathrm{al}^{19}$ in 1990 reported a series of 5 similar patients. In their review of the literature they felt the likely cause of this acquired aganglionosis was ischemia of the pulled through bowel or transient hypoxic episodes during the recovery period. Clearly, accurate biopsy results are critical, as shown by our 1 patient who had an incorrect diagnosis of aganglionosis before reoperation.

Stricture formation secondary to complications of the initial pull-through was the most common cause for performing a redo pull-through. The incidence of strictures varies from $3 \%$ to $35 \%$ between series and most can clearly be handled with repeated dilations. ${ }^{12,13,20-23}$ The incidence of anastomotic leak varies from $1.5 \%$ to $8 \%$ in these series and does not necessarily portend stricture formation. It was noted in our series that most strictures were associated with an early leak after the initial pull-through (75\%).

Total colonic aganglionosis (TCA) continues to be a challenge with significant postoperative morbidity. Many series evaluating this patient subgroup have shown that these patients undergo multiple surgical procedures with gradual improvement in function over time. ${ }^{24-26}$ Our own patient with TCA in this series was not different and underwent at least 8 surgical procedures including 2 pull-throughs. She continues to have an average of 10 bowel movements per day and differs from the others in our series in whom the number of bowel movements per day has decreased over time.

Although the mortality rate for enterocolitis associated with Hirschsprung's disease has decrease dramatically over time, it has remained a significant cause of morbidity before and after pull-through procedures. Six of our patients had episodes of enterocolitis requiring hospitalization before their reoperation. All of these children had another indication for reoperation other than enterocolitis alone, but most experienced improvement in symptoms of enterocolitis as well. Only 1 of those 6 had episodes of enterocolitis requiring hospitalization after repeat pull- 
through. In the other 5 referenced series of redo operations, two additional patients underwent a pull-through because of intractable enterocolitis. These two patients also saw an improvement in their symptoms postredo. Enterocolitis continues to require aggressive management and close long-term follow-up. Despite the improvement in symptoms in our redo patients, medical management such as the use of chronic metronidazole or occasionally a sphincterotomy should be considered first.

Hirschsprung's disease remains a condition with a wide variety of presentations, clinical courses, and outcomes. Evaluation of the subgroup requiring redo pullthroughs shows the same varied indications for interven- tion but a generally favorable outcome. Most patients in this subgroup have a mechanical cause of failure of their first operation, and the indications for reoperation are clear. Aggressive use of rectal biopsy in patients having difficulty with persistent obstruction and colonic dilatation may reveal the group of patients with acquired aganglionosis who receive equal benefit from reoperation as the group with mechanical indications. The choice of type of reoperation remains that of the surgeon, but we have shown that an endorectal pull-through is a valid choice for reoperation, can be performed in a technically straightforward fashion, and has excellent outcome in terms of improvement in symptoms and stooling patterns.

\section{REFERENCES}

1. Swenson O, Bill AH: Resection of rectum and rectosigmoid with preservation of the sphincter for benign spastic lesions producing megacolon: An experimental study. Surgery 24:212-220, 1948

2. Langer JC, Minkes RK, Mazziotti MV, et al: Transanal one-stage Soave procedure for infants with Hirschsprung's disease. J Pediatr Surg 34:148-151, 1999

3. Duhamel B: Retrorectal and transanal pull-through procedure for the treatment of Hirschsprung's disease. Dis Colon Rectum 7:455-458, 1964

4. Soave F: Hirschsprung's disease: A new surgical technique. Arch Dis Child 39:116-124, 1964

5. Boley S: New modification of the surgical treatment of Hirschsprung's disease. Surgery 56:1015-1017, 1964

6. Martin L, Caudill D: A method for elimination of the blind rectal pouch in the Duhamel operation for Hirschsprung's disease. Surgery 62:951-953, 1967

7. Coran AG, Weintraub WH: Modification of the endorectal procedure for Hirschsprung's disease. Surgery 143:951-953, 1976

8. Elhalaby EA, Coran AG, Blane CE, et al: Enterocolitis associated with Hirschsprung's disease: A clinical-radiological characterization based on 168 patients. J Pediatr Surg 30:76-83, 1995

9. Rescorla FJ, Morrison AM, Engles D, et al: Hirschsprung's disease: Evaluation of mortality and long-term function in 260 cases. Arch Surg 127:934-942, 1992

10. Erdek MA, Wilt E: Hirschsprung's disease: One institution's ten year experience and long-term follow-up. Am Surg 60:625-628, 1994

11. Heij HA, de Vries X, Bremer I, et al: Long-term anorectal function after Duhamel operation for Hirschsprung's disease. J Pediatr Surg 30:430-432, 1995

12. Marty TL, Seo T, Matlak ME, et al: Gastrointestinal function after surgical correction of Hirschsprung's disease: Long-term follow-up in 135 patients. J Pediatr Surg 30:665-658, 1995

13. Fortuna RS, Weber TR, Tracy TF, et al: Critical analysis of the operative treatment of Hirschsprung's disease. Arch Surg 131:520-525, 1996
14. So HB, Becker JM, Schwartz DL, et al: Eighteen years' experience with neonatal Hirschsprung's disease treated by endorectal pull-through without colostomy. J Pediatr Surg 33:673-675, 1998

15. Wilcox DT, Kiely EM: Repeat pull-through for Hirschsprung's disease. J Pediatr Surg 33:1507-1509, 1998

16. Sarioglu A, Cahit Tanyel F, Buyukpamukcu N, et al: Redo operations of Hirschsprung's disease. Int Surg 83:333-335, 1998

17. Weber TR, Fortuna RS, Silen ML, et al: Reoperation for Hirschsprung's disease. J Pediatr Surg 34:153-157, 1999

18. Langer J: Repeat pull-through surgery for complicated Hirschsprung's disease: Indications, techniques, and results. J Pediatr Surg 34:1136-1141, 1999

19. West KW, Grosfeld JL, Rescorla FJ, et al: Acquired aganglionosis: A rare occurrence following pull-through procedures for Hirschsprung's disease. J Pediatr Surg 25:104-109, 1990

20. Polley TZ, Coran AG, Wesley JR: A ten-year experience with ninety-two cases of Hirschsprung's disease. Ann Surg 202:349-355, 1985

21. Agarwala S, Bhatnagar V, Mitra DK: Long-term follow-up of Hirschsprung's disease: Review of early and late complications. Indian Pediatrics 33:382-386, 1996

22. Tariq GM, Brereton RJ, Wright VM: Complications of endorectal pull-through for Hirschsprung's disease. J Pediatr Surg 26:12021206, 1991

23. Moore SW, Albertyn R, Cywes S: Clinical outcome and longterm quality of life after surgical correction of Hirschsprung's disease. J Pediatr Surg 31:1496-1502, 1996

24. Tsuji H, Spitz L, Kiely EM, et al: Management and long-term follow-up of infants with total colonic aganglionosis. J Pediatr Surg 34:158-162, 1999

25. Hoehner JC, Ein SH, Shandling B, et al: Long-term morbidity in total colonic aganglionosis. J Pediatr Surg 33:961-966, 1998

26. Endo M, Watanabe K, Fuchimoto Y, et al: Long-term results of surgical treatment in infants with total colonic aganglionosis. J Pediatr Surg 29:1310-1314, 1994

\section{Discussion}

K. Georgeson (Birmingham, $A L$ ): I think this paper points out something that many of us with gray hair have seen, and that is that not all of our patients do well.

The 1 issue that we have seen and puzzled over, and I wonder if you have an answer for, is where you have clear evidence of biopsy-proven ganglion cells at one time and then later come back and find no ganglion cells, and sometimes that can be a fairly extensive length. Would you try to explain that for me?

K. Van Leeuwen (response): Dr West and Dr Grosfeld 
put together a review of the literature in 1995. And the going theory at that time was ischemia, either at the time of operation or in the early postoperative period.

I think the best guess short of the ischemia answer is, inconsistent pathology results.

J.C. Langer (Toronto, Ontario): I would offer another explanation in some of these patients. I think that some of them lose their ganglion cells. I think it is a subtype of Hirschsprung's patients where there is some kind of active process going on. Some of those patients also will have intestinal neuroanal dysplasia or motility disorders proximally.
So I have made the habit in a case like this in which there is recurrent or residual aganglionosis to do laparoscopic colon biopsies all the way around. Because if you find IND in the left side of the colon, which happens sometimes, and you have normal enervation on the right side, then when you redo your pull-through, you probably should be taking out the IND bowel as well. The same thing can be done using colonic motility studies. Sometimes you will find abnormalities on the left side and not on the right side, so it changes the kind of pull-through you do. 